\title{
Entre acequias y azarbes: el legado del agua en el entorno de la Albufera de Elche como revulsivo para un territorio
}

\author{
Margarita Guilló Durá1 y Juan Miguel Montaner Alonso ${ }^{2}$ \\ ${ }^{1}$ Associació per al Desenvolupament Rural del Camp d'Elx, info@turismeruralelx.es \\ 2Comunidad de Regantes de Carrizales, carrizales@carrizales.es
}

\begin{abstract}
Resumen. El entorno de la antigua Albufera de Elche, pese a atesorar valores culturales y ecológicos del máximo nivel, ha sido postergado, no sólo desde instituciones externas, sino desde las mismas administraciones locales. Los protagonistas reales del mantenimiento de este espacio, los diferentes sectores sociales de nuestro medio rural, somos conscientes del valor de esta herencia, y queremos luchar por nuestra supervivencia, en la difícil tesitura actual, aprovechando esta herencia única. Por ello, exponemos la experiencia sobre las iniciativas llevadas a cabo para intentar salvar nuestro patrimonio y, con él, nuestro mismo sentido de ser como colectividad, tanto desde la Associació per al Desenvolupament Rural del Camp d'Elx (ADR), como la Comunidad de Regantes de Carrizales, pionera en la visión integrada del desarrollo sostenible.
\end{abstract}

Palabras clave: desarrollo rural, turismo rural, patrimonio hidráulico, Elche, Carrizales de Elche

\begin{abstract}
The ancient wetland of the Albufera de Elche has important ecological and cultural values, not fully recognized by the local and regional administrations. The real protagonists of the conservation of this area, conscients of these values, struggle for their survival, using this valuable heritage. In this paper, the society for rural development Associació per al Desenvolupament Rural del Camp d'Elx (ADR) and the water users' association Comunidad de Regantes de Carrizales describe the actions recently developed to protect the natural and cultural heritage of the wetland.
\end{abstract}

Keywords: Rural development, rural tourism, water heritage, Elche, Carrizales de Elche

\section{Introducción}

Trataremos de recorrer a través del bolígrafo y la voz, las redes que el agua ha entretejido desde hace siglos en nuestra cultura. Con ello queremos transmitir la espectacularidad de un territorio en las orillas del "Sinus Ilicitanus" compartido por las Comarcas de la Vega Baja (o Bajo Segura) y el Bajo Vinalopó, al sur de la provincia de Alicante.

Nos basamos en la historia de este proceso natural y humano que es nuestra historia, la que actualmente tratamos de redactar forzando a golpe de teclas de ordenador, para que no se olvide ni se pierda su carácter natural, cultural, funcional, paisajístico, agrícola, pesquero, turístico y un sinfín de oportunidades más, que no todos los agentes intervinientes en el territorio entienden por igual.

ADR (Associació per al Desenvolupament Rural del Camp d'Elx) surge a finales de 2007, tras un periodo de varios meses de reflexión por parte de diferentes entidades vinculadas al mundo rural ilicitano, desde sindicatos agrarios a comunidades de regantes, productores, asociaciones vecinales de las pedanías, etc., preocupadas por encontrar alternativas que sacasen de la desilusión permanente a un sector agropecuario cansado de competir sólo por los precios, tentado día tras día por el sector inmobiliario como única alternativa posible de 
futuro, y del que los jóvenes se alejan en busca de cualquier otra forma de vida en el medio urbano.

Tabla 1. Asociaciones integradas en $A D R$

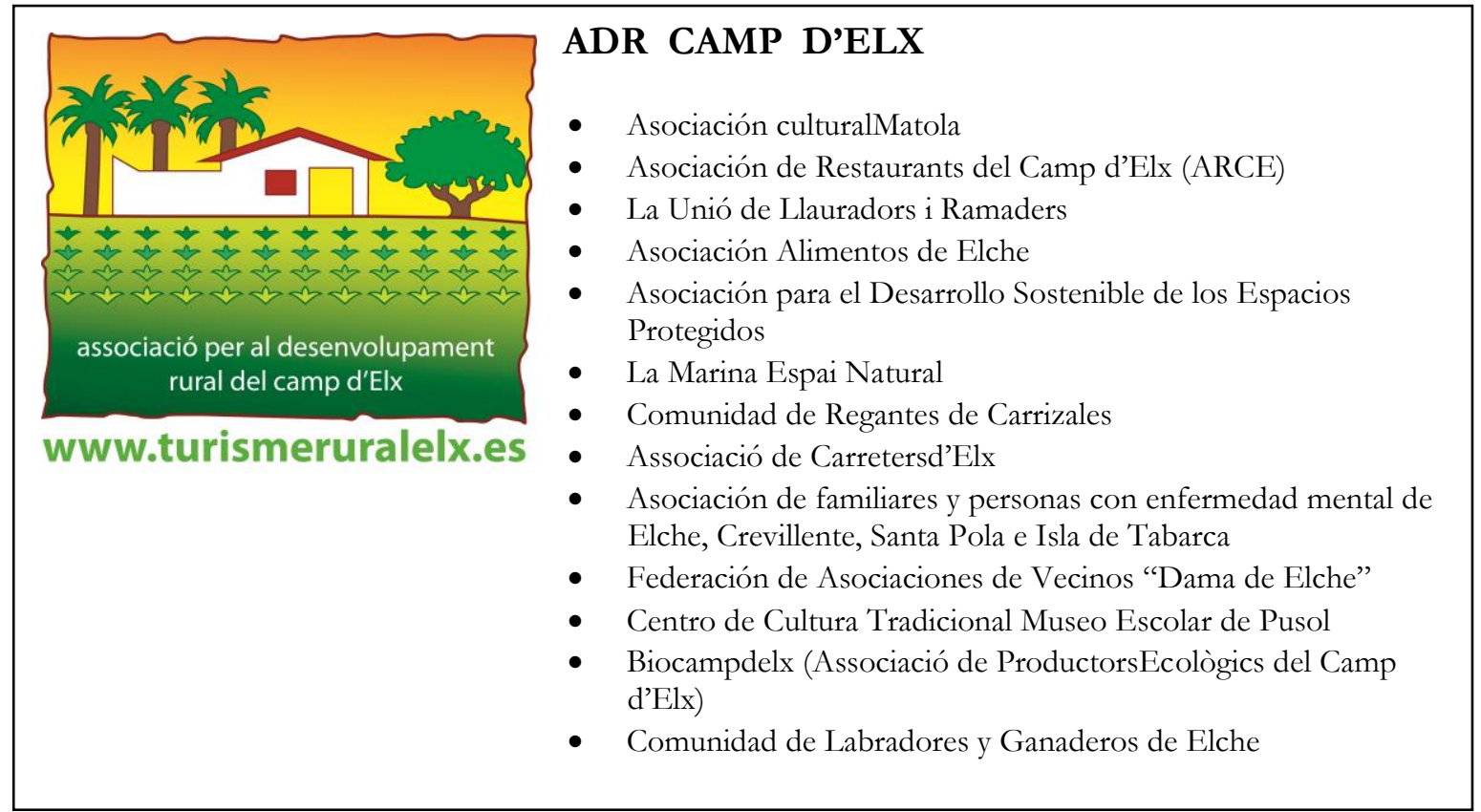

Nuestro objetivo, pues, como asociación cívica que aglutina hoy a otras 13asociaciones vinculadas a nuestro ámbito rural, más una veintena de sociedades o empresas a título particular, es complementar rentas de los habitantes del Camp d'Elx a través de actividades que pongan en valor esos valores del territorio, como el turismo rural o la promoción de valores añadidos en los productos rurales, lo cual requiere la visibilización de los diferentes patrimonios y usos del territorio. Para nosotros, uno de los valores eco-culturales más importantes es el Patrimonio Hidráulico que aún pervive y funciona y que da vida y sentido a un paisaje único al sur de la provincia de Alicante. Por ello, venimos esforzándonos en conectar, preservar, visibilizar y documentar una red aún en funcionamiento de cientos y cientos de kilómetros de azarbes y acequias (entre otras figuras de nuestro patrimonio hidráulico) que aprovecha aguas sobrantes de dos ríos, de dos sistemas fluviales que convergen en un mismo territorio. Esta red hidráulica, este patrimonio, funciona para regar y mantener los campos y las cosechas y para preservar y conservar territorio y paisaje (humedales, saladares, almarjales). Nuestro reto es mantener a los agricultores y a otros actores del medio rural en activo y que de forma digna se ganen el sustento o complementen sus rentas, de igual forma que conservemos territorio, paisaje y patrimonio hidráulico de gran valor (Parque Natural de las Salinas, Parque Natural de El Hondo, Zona Húmeda de Carrissals, y un largo etcétera)

No sólo destacamos una red hidráulica que funciona heredada de los primeros pobladores de estas tierras, en algunos casos romanos y árabes ya señalaron muchos caminos del mapa del agua actual. También destacamos dos de las comunidades de regantes más antiguas de España si pensamos en las vinculadas a lasaguas del Pantano de Elche: la de la Acequia Mayor, mantenedora del Palmeral ilicitano, actual Patrimonio de la Humanidad, y la de la Acequia de Marchena. Pero la verdadera revolución se dio a inicios del siglo XX cuando se 
fundaron tres compañías de impulsión de aguas desde las cotas más bajas de la comarca vecina, el Bajo Segura conocido como la Vega Baja, hacia el Campo de Elche-Camp d’Elx: Nuevos Riegos el Progreso, La Real Compañía de Riegos de Levante y Riegos El Porvenir. Estas compañías transformaron el secano en regadío y así hicieron posible el desarrollo de una economía agrícola floreciente que incluso se extendió a través de canales y acequias a otras comarcas vecinas.

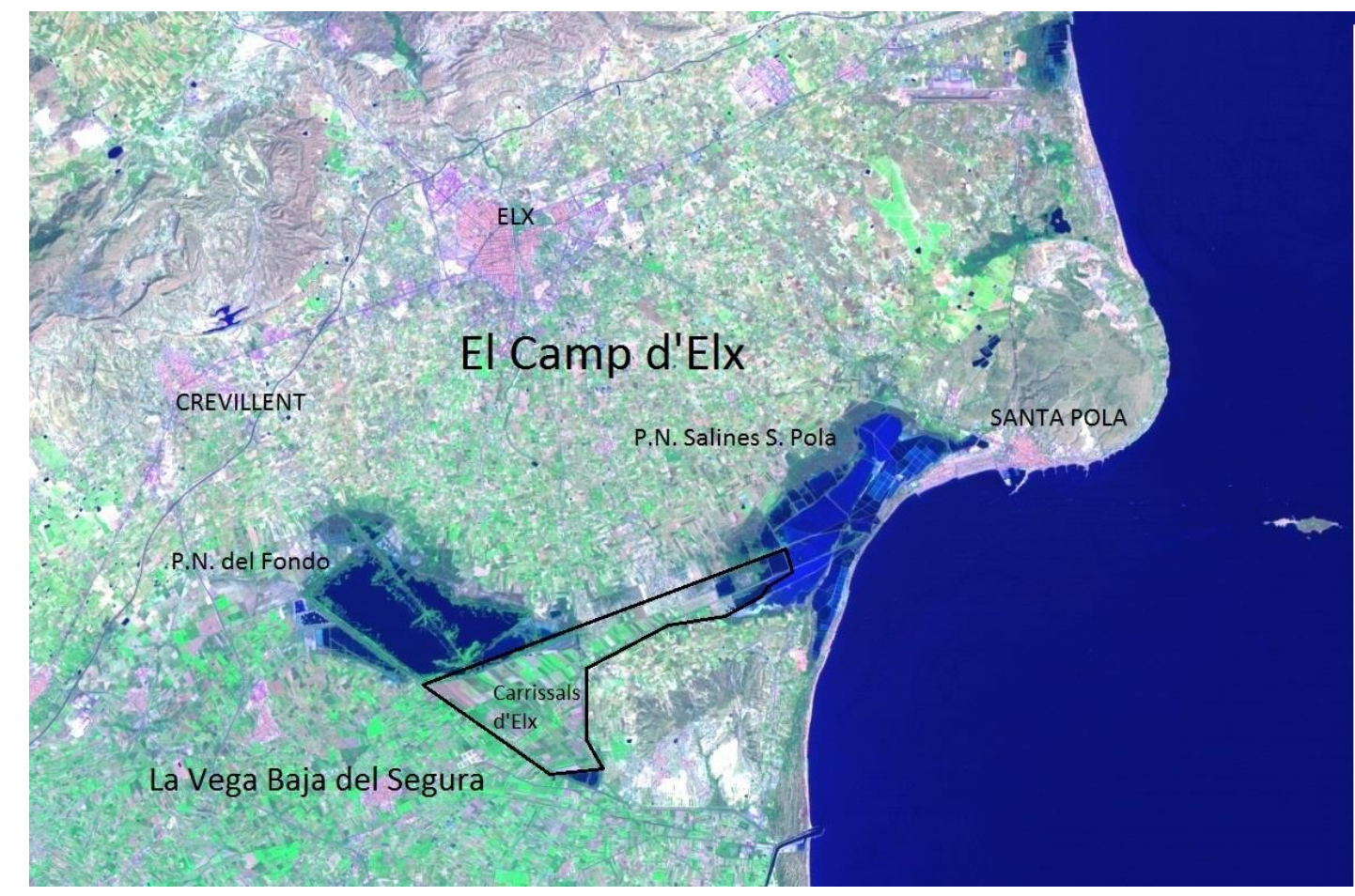

Fig.1. El Camp d'Elx y su entorno. Entre los dos Parques Naturales, y entre el Camp d'Elx y la Vega Baja del segura, el ámbito de los Carrizales.

\section{Actividades desarrolladas}

Entre otras acciones y con lo que respecta al patrimonio hidráulico y su funcionalidad el 24 de noviembre de 2009 firmamos el "Manifiesto de Guardamar" junto con muchas de las Comunidades de Regantes del Bajo Vinalopó y del Bajo Segura-Vega Baja e incluso otras organizaciones como el Colegio de Geógrafos de la Comunidad Valenciana o el Colegio de Licenciados en Ciencias Ambientales de la Comunidad Valenciana ${ }^{1}$. En el Manifiesto se apuesta por la vida rural, por el conocimiento del medio, su historia y su cultura que constituyen un patrimonio único ligado a un sistema de regadío de características singulares y fruto de la sapiencia hídrica multisecular. Se reconoce la labor de los agricultores durante siglos, de su sentido de la responsabilidad en la conservación del medio rural y natural para transmitir esa herencia a las generaciones futuras que están más acordes con las Directivas Europeas de Aguas y Paisaje que con algunas normativas autonómicas y locales. 


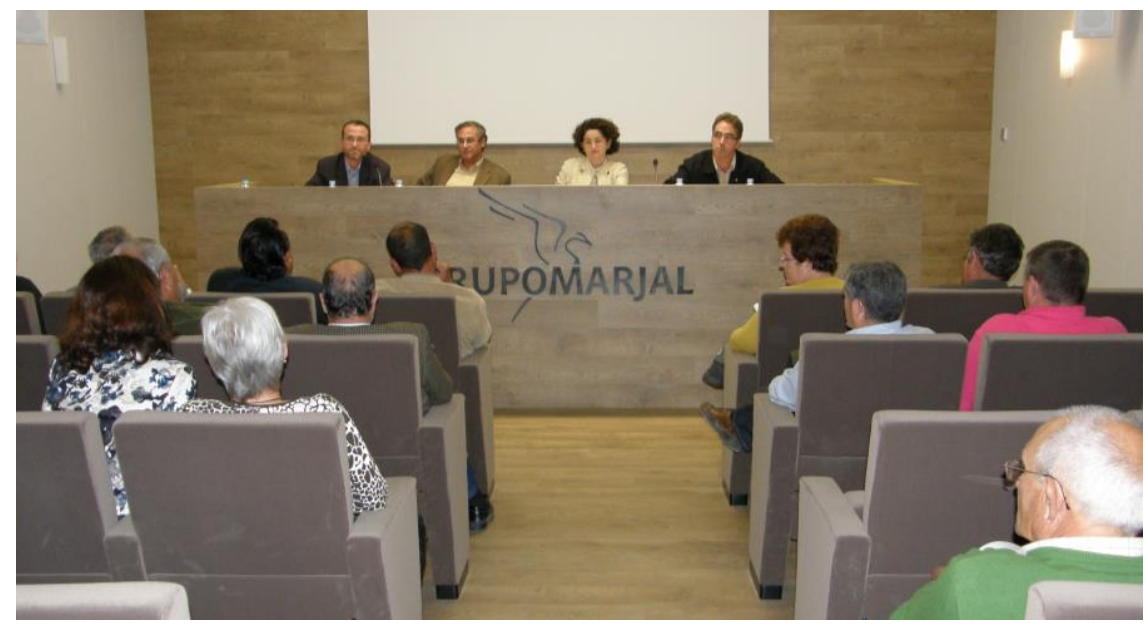

Fig.2.Acto de Firma del Manifiesto de Guardamar, 24 noviembre de 2011.

Entre otras, la riqueza de nuestro territorio estriba en la sabiduría de unas tierras con clima semiárido pasar a campos cultivables, a ricas huertas que han dado a la actividad agraria y a sus gentes la posibilidad de vivir y permanecer aquí durante siglos. Sabiduría que ha permitido aprovechar los sobrantes del Río Segura y del Río Vinalopó, dividir el agua en hilos en tiempo de los árabes aprovechando la sombra de las palmeras, para contar con una floreciente agricultura que da sentido al Patrimonio de la Humanidad UNESCO del Palmeral de Elche y que aún lo mantiene (Comunidad de regantes de la Acequia Mayor del Pantano y de la Acequia de Marchena). Esa sabiduría aún se mantiene con la Comunidad de regantes de l'Assut dels Moros aguas abajo del Río Vinalopó. Como luego se detallará, en el s.XVIII y con las obras del Duque de Arcos, en paralelo a las del Cardenal Belluga, se crea la Comunidad de Regantes dels Carrissals vinculada a los sobrantes de aguas del Río Segura que indican aprovechamientos de la misma3, 4 y hasta 5 veces (reciclaje hídrico único en el mundo). Sabiduría del reciclaje que en 1906 lleva a la creación de la compañía Nuevos Riegos el Progreso S.A y a impulsar aguas hacia el campo de Elche, también surgió Riegos El Porvenir y la gran Compañía de Riegos de Levante, la mayor empresa de irrigación de España y de Europa que gracias a que embalsaba las aguas de riego en una zona conocida como el Fondo (Hondo), hoy en día contamos con una de los más valiosos ecosistemas del Mediterráneo: el Parque Natural del Hondo.

Y volvemos a reseñar a las Comunidades de regantes del Campo de Elche-Camp d'Elx:

- Comunidad de regantes Acequia Mayor del Pantano

- Comunidad de regantes Acequia de Marchena

- Comunidad de regantes Assut dels Moros que hoy en día aprovecha, como las anteriores, sobrantes de la depuradora de Algorós en Elche de la $\mathrm{CHJ}$

- Comunidad de regantes de Carrissals

- Nuevos Riegos El Progreso S.A

- Riegos el Porvenir

- Riegos de Levante

Su labor, estatutos, normativas tiene mucho que agradecer a los romanos y árabes que vivieron antes en estas tierras y dejaron mucho trabajo hecho, pero también se ha de agradecer y mirarse en las comunidades que por todo el Bajo Segura-Vega Baja mantienen azarbes y azarbetas y en muchos casos los niveles de aguas que permiten en la actualidad 
seguir impulsando aguas contra la gravedad desde cotas cercanas a los 0 metros hacia el campo de Elche, y que también nos permiten mantener espacios naturales, paisaje y vida allí donde llegan, por ello también hemos de reconocer y agradecer la labor de Comunidades de regantes de Almoradí, de Orihuela, de Rojales, de Dolores, de Guardamar, de San Felipe Neri, o San Isidro-El Realengo en Crevillente o de Riegos de Levante Margen Derecha del Segura, entre otras, todas ellas en la demarcación de la CHS.

Es el territorio el que da posibilidades y también el que nos pide a gritos cuidados cuando los necesita, si en la Edad Media y bien entrado el s. XVIII el sistema lagunar de almarjales y saladares permitía vivir a nuestros antepasados de la sosa y sus derivados (se convertía en lejías, jabones y vidrio) o de la pesca a los nobles y a la Villa, hoy en día estas tierras han dado lugar a una agricultura de olores y sabores muy especiales, condicionados por las peculiaridades ambientales del territorio, entre los que destacan productos apreciados en el mercado como el "Melón de Carrizales" o que pueden complementar rentas aparte de cultivar alcachofas y granados entre otros cultivos, haciendo de estos espacios paraísos para las aves, su nidificación y paraísos naturales que puedan visitar cicloturistas, senderistas, ornitólogos, etc. Los usos cambian, pero las tierras y sus paisajes

se han de seguir manteniendo para ello.

\section{Obras que ponen en peligro un paraje natural}

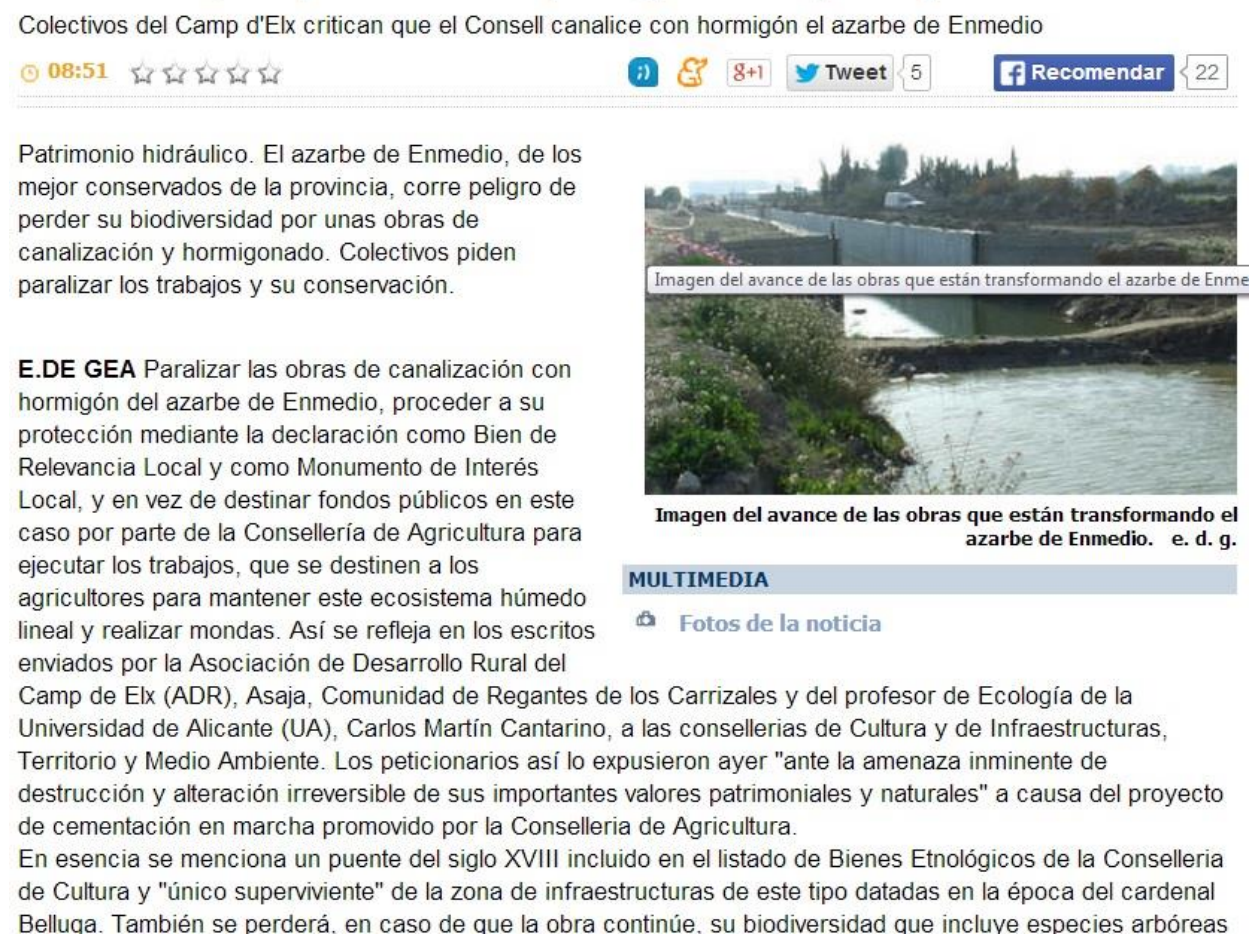

Fig.3. Noticia en el periódico Información: marzo 2012.

Nuestro reto hoy en día es mantener y conservar paisaje y el patrimonio hidráulico y su funcionalidad es clave para ello:

- cómo mantener los campos cultivados, que dependen de las sobrantes del río Segura en la Vega Baja y en el Campo de Elche 
- cómo mantener los espacios naturales del Parque Natural del Hondo o de las Salinas de Santa Pola, también dependientes en buena parte de dichas sobrantes

- cómo obtener un reconocimiento del valor de nuestro patrimonio histórico-cultural hidráulico o, en general, del medio rural $^{2}$, cuando nunca ha merecido atención por nuestras administraciones, pese a que la Comunidad Valenciana es referente mundial en la temática del regadío histórico. Y como muestra, un ejemplo: hasta ahora ningún elemento rural ni hidráulico aparece ni siquiera catalogado oficialmente como elemento cultural por el Ayuntamiento de Elche, a excepción del BIC del Pantano, y ningún elemento del inmenso patrimonio del regadío de la comarca del Bajo Segura, el segundo espacio de huerta histórica de la Comunidad Valenciana, tiene la consideración ni de BIC ni de BRL, es decir, no figura en el catálogo valenciano de elementos patrimoniales.

- cómo mantener, desbrozar y mondar las azarbes para permitir el paso del agua, y por tanto la funcionalidad del sistema agrario, y así mantener su biodiversidad y su valor paisajístico, sin que ello suponga una carga insostenible para los regantes.

- cómo hacer frente a la tendencia, promovida incomprensiblemente por nuestra Administración, a la cementación, el hormigonado o incluso entubado de azarbes de recogida de aguas, lo que impide el crecimiento de árboles y plantas que filtran las aguas y favorecen la biodepuración natural de las mismas, no previenen avenidas, impiden nidificación o asentamiento de aves, destruyen patrimonio heredado de nuestros antepasados y elementos históricos muy importantes o que dieron el origen a esas tierras, impiden pasear al lado de la lámina de agua, destruyen los referentes paisajísticos de un entorno marcado y cruzado por un sistema de azarbes y canales único en el mundo y que podría ser referente de un producto y un destino turístico de gran personalidad...

- cómo sensibilizar a nuestras administraciones locales, autonómicas y estatales: ayuntamientos, comunidad autónoma valenciana, Confederación Hidrográfica del Júcar, Confederación hidrográfica del Segura entre otras) para que adopten políticas integradoras, realistas, sensibles, y en la línea de lo que se viene haciendo en los países de nuestro entorno.

- cómo convencer a las diferentes comunidades y sindicatos de regantes, así como a las empresas y entidades cívicas, de la necesidad de estar unidos y de la relevancia e importancia del bien que manejan o disfrutan a diario (el agua, su distribución, su estructura de reparto, su canalización, ...) 


\section{Denuncian el derribo de los restos de un molino de agua junto al Pantano}

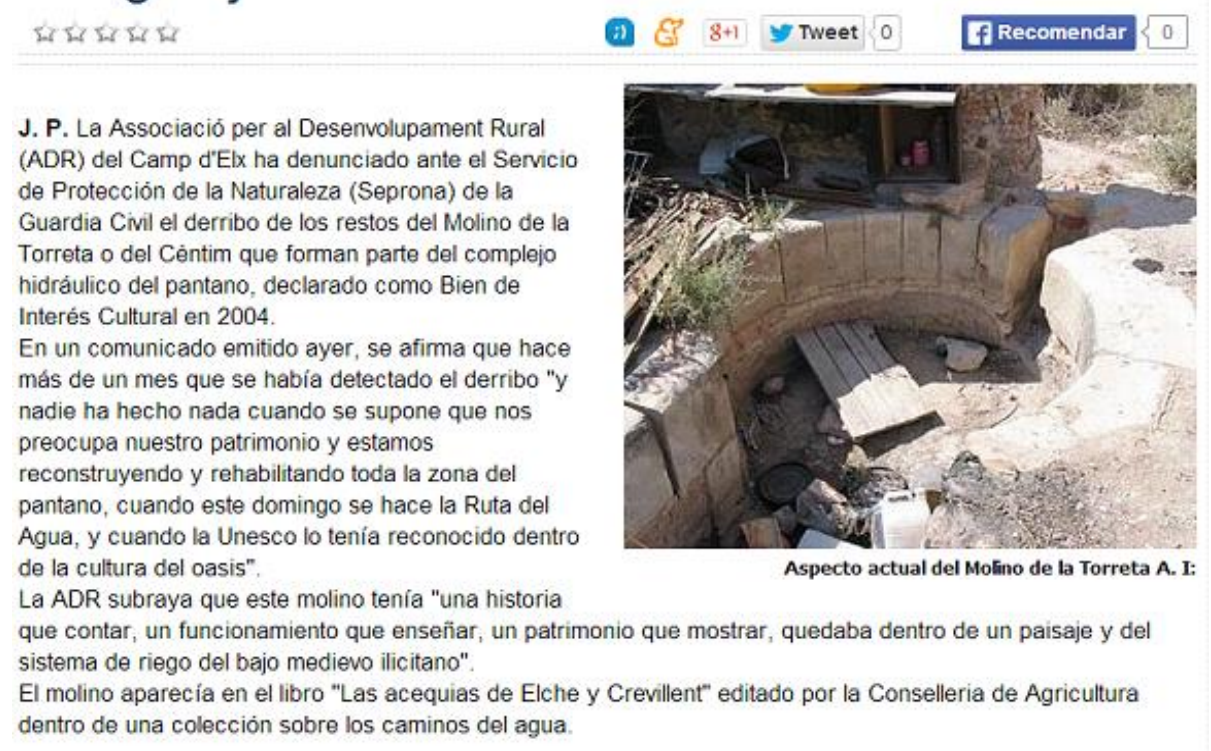

Fig. 4: Noticia en el periódico Información, 20 de junio de 2008.

lo útil y funcional y su decisiva importancia para la supervivencia de agricultura y ganadería no quita, no excluye, no impide el desarrollo de otras alternativas culturales y turísticas que le darían más valor si cabe y una funcionalidad innovadora y mantenedora de patrimonio y paisaje y por tanto de dinamización ciudadana y visitantes, de biodiversidad, de vida.

\section{Sorprendidos con la riqueza del agua \\ Unas 200 personas recorren el patrimonio hidráulico de la ciudad con visitas a las acequias y comunidades de regantes \\ A. FAJARDO | 30.09.2013 | 09:30 \\ La ciudad de las palmeras no podría entenderse de otra manera sin su patrimonio hidráulico. $Y$ ayer, con motivo del Día Mundial del Turismo, los ilicitanos comprobaron de primera mano una de las razones que explican por qué el palmeral es Patrimonio de la Humanidad. En bici o a pie, vecinos del municipio realizaron visitas a las acequias y comunidades de regantes del término municipal. \\ Sorprendidos y cautivados por la historia y la importancia del patrimonio hidráulico de la ciudad. Así se mostraron ayer los ilicitanos que asistieron a las actividades organizadas con motivo del Día Mundial del Turismo.

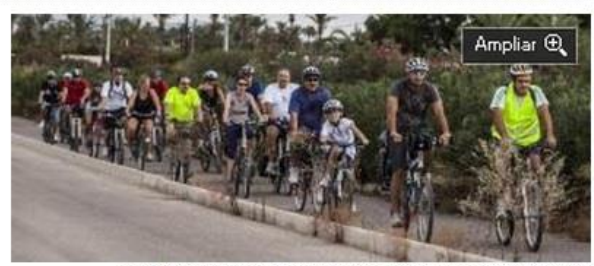 \\ Los ilicitanos realizaron ayer una ruta en bici por la desembocadura del río Vinalopó. sergio ferrández \\ Fotos de la noticia \\ $Y$ es que, durante toda la mañana, los \\ participantes realizaron la popular Ruta del Agua guiada por integrantes de la Comunidad de la \\ Acequia Mayor del Pantano, una expedición por los Motores de Sivaes de la Sociedad Riegos El \\ Progreso, guiada por ellos mismos, y una tercera visita en bicicleta por todo el río Vinalopó hasta su desembocadura en l'Assarb de Dalt, que trae sobrantes de riego de todo el sistema del Bajo Segura- Vega Baja.}

Fig. 5. Noticia en el periódico Información: Excursión del 29 de septiembre 2013. 
En estos años ADR ha llevado a cabo diferentes iniciativas para visibilizar este patrimonio postergado, y procurar favorecer a los productores que lo mantienen. Igualmente, venimos manteniendo reuniones con administraciones locales, regionales y nacionales. Disponemos una página web (turismoruralelche.es) donde mostramos nuestras actividades y difundimos las noticias relevantes para nuestros asociados y, en general, las personas interesadas en el ámbito rural ilicitano y sus valores o aquellas que quieran conocerlo.

ADR, ya lo hemos dicho, es una asociación de asociaciones que nació y actúa como potenciadora de las iniciativas de sus muy diferentes miembros, siempre en defensa de la sostenibilidad de nuestro territorio. De todas las Comunidades de Regantes del territorio que nos atañe y nos preocupa, la de Carrizales, vínculo entre la Vega Baja del Segura y el Camp d'Elx,es una de las que desarrolla una de las más importantes labores de sostenibilidad en el territorio y que aquí representa un esfuerzo de promoción de nuestros intereses comunes especialmente activo.

\section{El caso de Carrizales: hacia un modelo agroecológico sostenible}

La Comunidad de Regantes de Los Carrizales de Elche es una comunidad de actividad eminentemente agrícola, con orígenes en el siglo XVIII, que presenta un problema característico del mundo rural como es la falta de rentabilidad de la actividad agraria y el consecuente problema de la falta de relevo generacional que asegure la continuidad de dicha actividad y, por tanto, la conservación del paisaje y de sus valores ecológicos y culturales. Intentaremos resumir la estrategia que está siguiendo la Comunidad, integrada en ADR desde la fundación de ésta, para intentar superar dicho problema.

\subsection{Carrizales, entre historia y ecología}

El paraje de Carrizales ("ElsCarrissars") está ubicado hidrológicamente en la Vega Baja del Segura pero en término ilicitano, a escasos kilómetros al sur de Elche, entre los Parques Naturales de El Hondo y de las Salinas de Santa Pola, constituyendo el nexo físico de unión y verdadero corredor ecológico entre ambos humedales. Posee una superficie de unas 1300 Ha., de las que 1.100 son huerta de regadío tradicional y el resto son charcas con actividad pesquera y cinegética, de una gran importancia ecológica y ornitológica. La propiedad está repartida entre cerca de cuatrocientos propietarios, por lo que abunda el minifundismo.

El Bajo Seguraestá conformado como una llanura de origen aluvial formada por los depósitos sedimentarios de los ríos Segura y Vinalopó. Las pruebas geológicas coinciden en el carácter pantanoso de la región durante, al menos, todo el Holoceno. La primera referencia a la geografía de la Vega aparece en la Ora Maritima de Rufo FestoAvieno, que en el siglo IV, y apoyándose en referencias de geógrafos muy anteriores a su época, escribió un poema en el que describía las costas entre las actuales Cádiz y Marsella; en él, al citar esta zona del litoral, lo define como extensamente arenoso, penetrando las arenas hacia el interior, donde se ubica un amplio pantano por el que reptan las aguas del Theodorus (= Thader $=$ Segura). Es lo que los romanos citaban como SinusIllicitanus, un arco de territorio inundado entre Santa Pola, Elche, Albatera, Orihuela y Guardamar, separado del mar por una barra de arena casi lineal, orientada N-S, que va todavía hoy desde Santa Pola hasta Guardamar, con el apoyo intermedio de la pequeña Sierra del Molar. En esa marisma desembocaban los ríos Vinalopó, al Noroeste, y Segura, por el Suroeste. 
En el siglo $\mathrm{X}$ se citan por primera vez actuaciones encaminadas al aprovechamiento agrícola de la Vega, mediante técnicas hidráulicas importadas por mercenarios egipcios que, tras la pacificación de Al-Andalus, se asentaron entre Murcia y Orihuela. Las crónicas de aquella época hablan de una acequia que, desde Orihuela, se dirigía hacia Al-Quatrullât (Catral) y terminaba en las proximidades de Al-Muwallidîn (Almoradî). Parece tratarse de una canalización para aprovechar las tierras próximas a la plaza fuerte de Orihuela, quedando el resto en su estado natural hasta la desembocadura.

En los siglos posteriores se continuaron explotando las mismas áreas, hasta que en el XVIII el Cardenal Belluga decide eliminar los focos de enfermedades infecciosas que eran las aguas pantanosas, y recuperar las nuevas tierras para uso agrícola. Se ponen así en marcha las labores de drenaje mediante zanjas interconectadas que rebajan el nivel freático, los llamados azarbes, y se obliga al río a discurrir por el extremo Sur de la Vega mediante la construcción de diques que reciben el nombre local de motas. De esta forma, el nivel de las tierras de cultivo quedaba por debajo del de las aguas fluviales, lo que permitía el riego mediante simples tomas por gravedad a través de las motas, a la vez que el propio riego con agua dulce lixiviaba las sales de las tierras recuperadas. Como contrapartida se tiene que, desde entonces, en momentos de grandes crecidas del río Segura, las motas se rompen o desbordan, con lo que se inunda casi toda la Vega, pero es un riesgo asumido y compensado por la riqueza de las tierras.

El sistema de riego de la huerta del Segura es uno de los sistemas de riego históricos más complejos que se conocen en el mundo. El sistema de la huerta del Segura, que debe hacer frente a las condiciones subdesérticas del SE ibérico, se ha ido construyendo históricamente sobre el principio básico de la reutilización al máximo del agua. Por otro lado, y dadas las condiciones de relieve y subsuelo de la vega del Segura, el sistema necesita de dos sistemas de canalizaciones paralelos: uno de irrigación y otro de drenaje. Así, el agua tomada del río por alguno de sus presas o azudes históricos (nueve en total, desde la Contraparada de Murcia hasta el azud de Guardamar) se desvía mediante acequias, que a su vez se dividen y subdividen en canales más pequeños, hasta llegar a cada campo. El agua empleada en regar una parcela quedaría empantanada si una vez filtrada por la tierra no fuese canalizada y extraída mediante zanjas de drenaje o escorredores, que a su vez confluyen en otras mayores o azarbetas, que terminan desembocando en grandes colectores denominados azarbes. Los azarbes se encargan de expulsar el agua de nuevo al río o (en el caso de Carrizales) directamente al mar. Pero antes de eso (y aquí reside la peculiaridad del sistema de la Vega Baja) esas aguas ya usadas para regar pueden ser, y de hecho son aprovechadas para regar otros campos no solo una sino varias veces.

Es la colonización emprendida por Belluga en el vecino territorio de las Pías Fundaciones lo que motiva al Duque de Arcos a desecar y colonizar a su vez el almarjal denominado "Els Carrissars" o "Bassa Llarguera" (Carrizales) también a principios del S XVIII. Por tanto, Carrizales ocupa el lugar de una antigua marisma que fue desecada y transformada en tierras de cultivo, quedando configurado un territorio constituido por parcelas agrícolas surcadas por una serie de acequias de riego y, sobre todo, por una densa red de canales de drenaje. Conservamos cerca de $200 \mathrm{Km}$ de estos canales excavados en la tierra tal y como se construyeron hace casi trescientos años y que representan el eje vertebrador de todo un agroecosistema de huerta tradicional ${ }^{3}$.

La transformación del antiguo almarjal en huerta produjo un cambio en el ecosistema alterándose la biodiversidad del mismo y configurándose un nuevo ecosistema antropizado. Una huerta rica y variada con distintos cultivos a lo largo del año tales como hortalizas de 
invierno, cereales, prados forrajero, frutales de verano y arbolado de todo tipo, junto con el mantenimiento de un flujo continuo de agua en los canales de drenaje, constituyen la base de la biodiversidad del territorio ${ }^{3,4}$ El nuevo ecosistema de huerta tradicional resulta del ensamblaje de los ecosistemas acuático y terrestre ${ }^{5}$.

Parte del territorio de Carrizales está incluida en el Parque Natural de las Salinas de Santa Pola y buena parte del resto corresponde a las Zonas de Amortiguación de Impactos de este Parque y del de El Hondo. Por otro lado, todo Carrizales se incluye en el ámbito del PORN del Sistema de Zonas Húmedas del Sur de Alicante, formado por los dos Parques mencionados y el de las Laguna de La Mata y Torrevieja. Por último, Carrizales ha sido considerado oficialmente Zona Húmeda, en atención a la densidad de su red hidráulica y su papel de corredor ecológico entre los dos Parques, y como tal figura en el Catálogo valenciano de Zonas Húmedas y en el Catálogo del Ministerio de Medio Ambiente.

Estos niveles de protección ecologista, que imponían toda una serie de prohibiciones de uso a nuestros comuneros, sin tener en cuenta nuestra historia, el verdadero funcionamiento del sistema y los derechos legítimos de agricultores y propietarios, provocó una situación de gran conflictividad, especialmente en la década de los 1990.

\subsection{Nuestros esfuerzos por mantener un patrimonio único}

La estrategia que venimos desarrollando está inspirada en el Modelo Agrario Europeo, que consiste en dar viabilidad a un territorio como zona económicamente funcional y ecológicamente mantenida. Para ello se debe de implantar un modelo de agricultura tradicional que produzca alimentos de calidad, que puedan salir al mercado con un valor añadido que mejore las rentas de los productores. Así mismo dicho modelo debe de ser respetuoso con el medio ambiente y favorecer la conservación del paisaje y de la biodiversidad.

La finalidad de este modelo es la de conseguir que al incrementar las rentas de los productores se consiga mantener empleo agrario; a la vez que potenciar un desarrollo económico de las zonas rurales haciéndolas atractivas al turismo rural mediante la conservación de los paisajes cultural y natural. En 2007 formamos parte de las asociaciones y entidades fundadoras de la Associació per al Desenvolupament Rural del Camp d'Elx (ADR). Entendemos que sólo mediante la sinergia de los diferentes sectores rurales ilicitanos (y también del complejo sistema de la Vega Baja del Segura, del que Carrizales forma parte directa, y del que el resto de Elche depende también de una forma u otra) podemos plantear las líneas de actuación integradas que necesitamos.

En el caso de Carrizales el mantenimiento de la actividad agraria, de la biodiversidad y del paisaje pasa, ante todo, por la conservación de nuestro denso sistema de regadío tradicional y del patrimonio hidráulico histórico con los canales de drenaje excavados en tierra ${ }^{3}$. Y ello, porque la actividad agraria se ve condicionada por el hecho de que el territorio se asienta sobre un acuífero salobre subyacente situado a algo menos de un metro de la superficie. Esto condiciona un flujo continuo de agua que por capilaridad asciende desde el acuífero hacia la superficie arrastrando sales y produciendo una progresivo deterioro de la calidad del suelo cultivable. Es gracias al riego por inundación que se evita la progresiva salinización del suelo debido a que el agua que filtra a través de la tierra arrastra de nuevo las sales hacia abajo, manteniéndose el suelo en un equilibrio salino dinámico.

Sin embargo, la implantación del sistema de riego localizado es una aspiración legítima de la Comunidad de Regantes de Carrizales como única forma real de desarrollar una 
horticultura competitiva, adaptada a los estándares de producción modernos y línea para asumir los cambios a los que se vea sometida la agricultura del futuro. La futura viabilidad del proyecto nos conducirá al mantenimiento de un doble sistema de regadío, sólo aparentemente antagónico, pues requerirá del uso alternado en una misma parcela de riego localizado para determinados cultivos y de riego por inundación para otros.

En el caso de los azarbes su importancia como ecosistema generador de biodiversidad está directamente relacionado con el sistema de riego por inundación, pues este sistema de riego es el responsable de proporcionar los caudales de agua dulce necesarios para mejorar las condiciones de ese ecosistema, ${ }^{3,4}$. Invertebrados, algas, briófitos, plantas vasculares y bacterias que pueblan el lecho, al igual que peces y demás organismos acuáticos son los responsables del trabajo de purificar el agua y de descomponer y reciclar los nutrientes. El agua que proviene del riego arrastra consigo parte del abono que se había incorporado a la tierra. Algas y demás vegetación serán las encargadas de asimilar esos nutrientes durante su trayecto hacia el mar. La siega regular de la vegetación de los taludes produce una mayor insolación, que a su vez provoca un incremento de la temperatura, con la consiguiente aceleración del proceso.

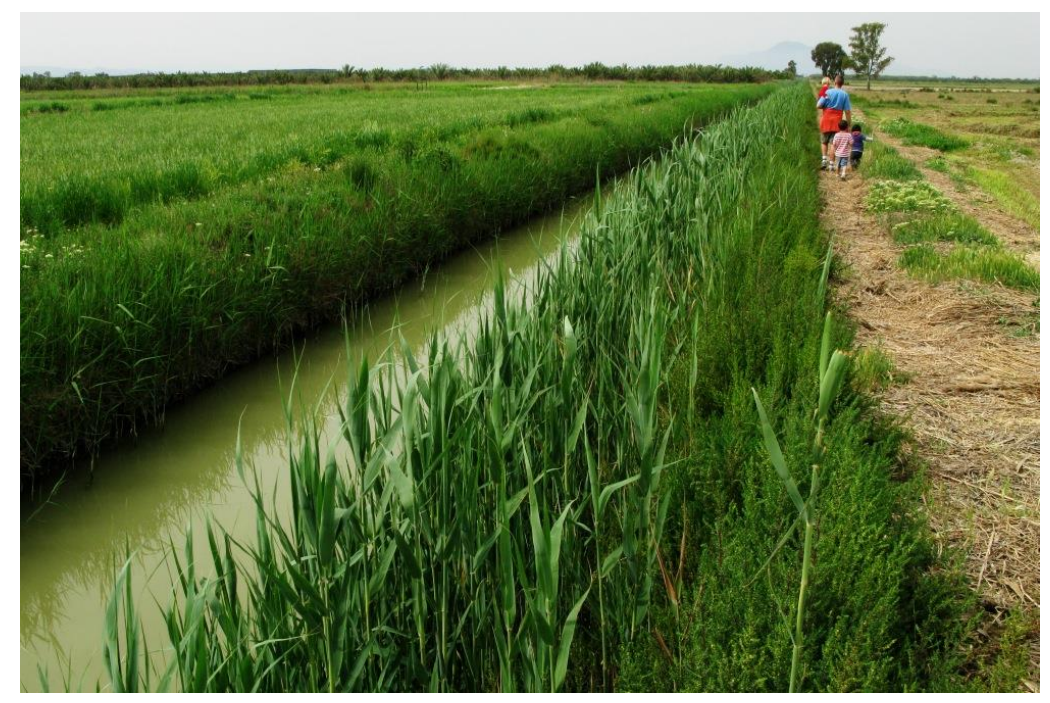

Fig. 6: Uno de los azarbes de Carrizales.

El Proyecto Carrizales nació como una continuidad del trabajo de investigación desarrollado por el Proyecto Europeo WADI, en el que se investigó el entorno del pantano del Hondo desde un punto de vista funcional y en el que se pretendió intentar darle una salida viable mediante la modificación de actitudes de agentes responsables de dicho funcionamiento $^{6}$. La Comunidad de regantes de Carrizales recogió la idea y se la presentó en el año 2008 al Conseller D. José Ramón García Antón donde se le expuso la iniciativa y se puso en marcha una comisión de trabajo para llevarla a cabo. Se llegaron a elaborar las líneas estratégicas para desarrollar el proyecto basadas en la implantación de la figura de un Parque Agrario. El prematuro fallecimiento del Sr García Antón privó al proyecto del apoyo político necesario y el proyecto fue olvidado por la administración.

Es a partir de aquí donde entra realmente en valor la citada modificación de actitudes del Proyecto WADI, pues algunos responsables del Proyecto Carrizales decidimos continuar por nuestra cuenta en la búsqueda de un modelo agrario realmente sostenible, que pueda funcionar sin ayuda de la administración, que haga viable el territorio de Carrizales. 
Tres son las características que definen este modelo:

- Como el proyecto se intenta desarrollar por voluntad propia de la Comunidad de Regantes carece de apoyo administrativo y de cualquier tipo de financiación. Lento desarrollo del proyecto que ha de ser sostenible desde el primer momento.

- Estrecha y continuada relación con universidades y grupos conservacionistas.

- Máximo respeto por la conservación del paisaje. La defensa de la naturaleza no sólo se interpreta como un medio para lograr objetivos sino como un fin en sí mismo.

Para iniciar el proyecto lo primero fue crear la marca del Parque Natural Agrario, inspirada por el caso del Parque Agrario del Bajo Llobregat, en Barcelona, conocida por la intervención de su Director, don Josep Montasell, en las Jornadas organizadas por Carrizales y el Proyecto WADI en 2009 y de manera directa por una visita posterior al mismo Parque Agrario del Llobregat
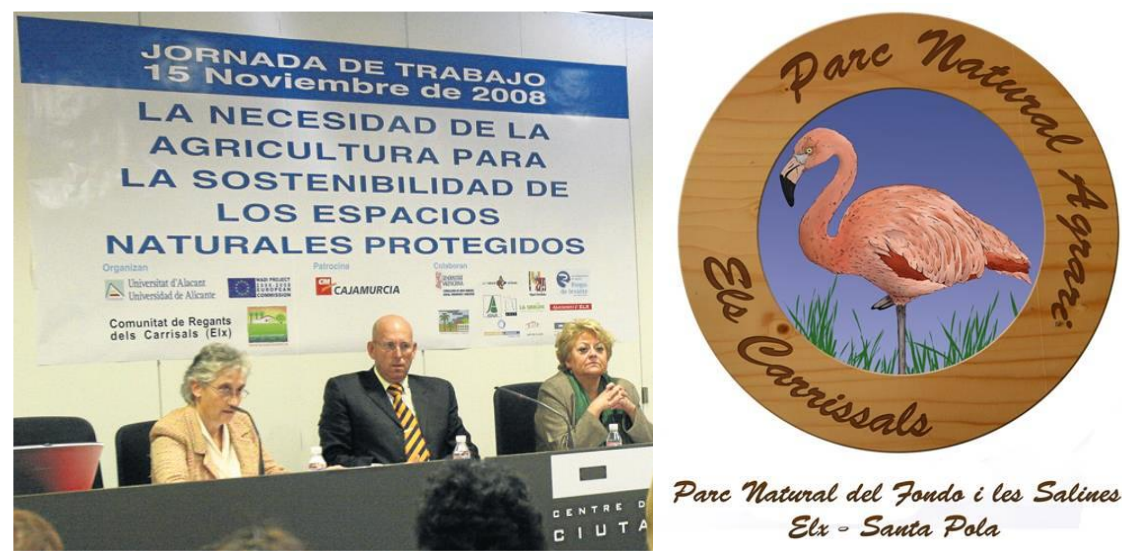

Fig. 7. Los Carrizales, Parque Natural Agrario, por voluntad de sus comuneros. A la izquierda, sesión de la Jornada de trabajo del 15 de noviembre de 2008 con representantes de ámbitos protegidos similares de España y Europa, en que se sentaron las bases para esta propuesta; a la derecha, el logo de nuestro Parque Natural Agrario.

La marca del Parque Natural Agrario es propiedad de la Comunidad de Regantes, que velará por el uso adecuado de la misma. A continuación se creó una pequeña cooperativa constituida por ocho agricultores que es la depositaria de la marca y la responsable de su uso. Los productos saldrán al mercado agrupados bajo el paraguas de una marca que los relacione con el territorio y que sea sinónimo de calidad para que les confiera un valor añadido que rentabilice la actividad agraria. Para alcanzar dicho fin hacemos uso de los valores naturales propios del territorio y de nuestras actuaciones medioambientales.

A continuación elegimos un producto estrella que la diera a conocer y luego lo publicitamos. Como producto estrella elegimos el melón, que dadas las particulares propiedades fisicoquímicas del terreno salobre en que nos encontramos adquiere un elevado dulzor y una pulpa crujiente, características estas muy apreciadas por los consumidores. 
El dulzor del melón es producto de la elevada salinidad del suelo, que al retener la humedad y dificultar la absorción del agua por parte de las raíces, empuja a las plantas a acumular en su interior una elevada concentración de sólidos solubles, que tenderán a acercar los diferentes potenciales osmóticos del substrato y del vegetal, haciendo así menos gravoso energéticamente para la planta el proceso de absorción del agua. El fruto se caracteriza por usar gran cantidad de azúcares como solutos.La pulpa crujiente es producto de la absorción por parte de las raíces de carbonatos presentes en el suelo y que se depositan sobre las paredes celulares del vegetal en forma de carbonato cálcico.

La difusión de la marca la realizamos sin coste alguno pues la Comunidad de Regantes carece de recursos económicos. Dicha difusión la realizan la prensa, radio y televisiones locales debido al interés que despierta el hecho de que una comunidad de agricultores se alíe con grupos conservacionistas para la defensa medioambiental de su territorio. Para ello es necesario que Proyecto, Territorio y Marca compartan el mismo nombre, así la marca se verá siempre publicitada con independencia del tipo de noticia.

Recientemente, hemos lanzado un nuevo portal web (www.carrizales.es) donde se intenta mostrar la íntima relación entre agricultura y ambiente en nuestro territorio, se ofrecen rutas y actividades y se difunden las actividades de la Comunidad y del Parque Natural Agrario.

Entre las muchas actuaciones medioambientales realizadas podemos mencionar:

- Labor de desbroce de los acueductos. Una de las principales características que diferencia Carrizales del resto de territorios del Bajo Segura es que los acueductos de avenamiento de Carrizales permanecen sin cementar, mientras que en el resto de la Vega están casi todos cementados o entubados.

Los pocos acueductos que se mantienen sin cementar deben ser sometidos a limpiezas periódicas del cauce para facilitar la libre circulación de los caudales de agua. Tradicionalmente existían tres tipos de limpieza: siega del carrizo y vegetación del talud, extracción de la vegetación acuática y extracción de lodos. Estos trabajos se vienen realizando con máquinas retroexcavadoras armadas de una pala cuchara que extraen barro y vegetación, para terminar luego aplicando un tratamiento de escarda química con herbicidas para mantener libres de vegetación por más tiempo los taludes.

En Carrizales, sin embargo, dichos trabajos se realizan sin necesidad de arrastrar los lodos del fondo ni de alterar los taludes debido al empleo de un invento propio en el que la pala ha sido substituida por una segadora de peine acoplada a una cesta con lo que se pueden realizar dichos trabajos sin afectar a las superficies del acueducto y quedando lecho y taludes intactos y, por tanto, la comunidad biótica asentada en los mismos sin alterar.

En la época de reproducción de las aves substituimos en la siega a la retroexcavadora por una pequeña embarcación con una segadora de peine montada a proa que se limita a cortarla ova y la vegetación que crecen en el centro del cauce, respetando por tanto los taludes y no interfiriendo en la nidificación. Así mismo tenemos totalmente prohibido el uso de herbicidas en los acueductos comunitarios. 


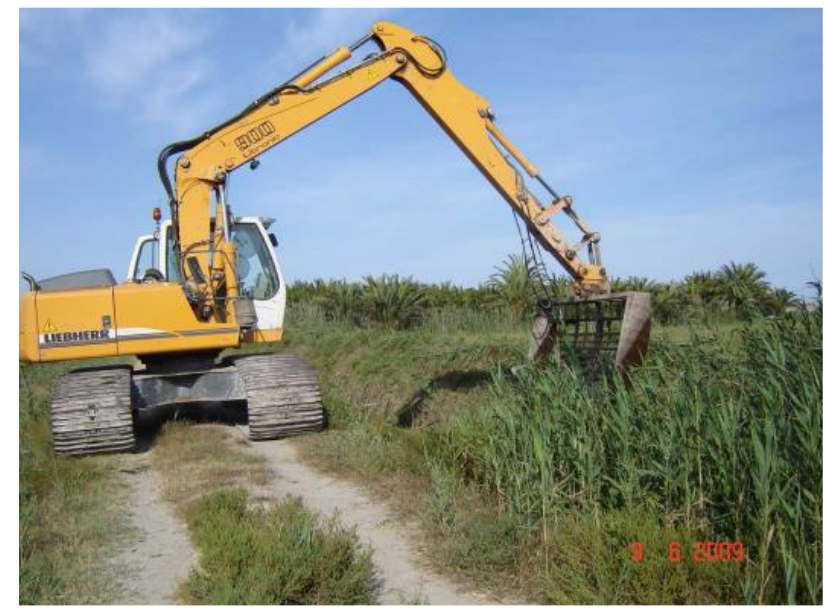

Fig. 9. La máquina utilizada para realizar las mondas de azarbes en Carrizales con el menor daño ecológico, invento de nuestros comuneros.

- Restauración del ecosistema natural antiguo de la zona: se denominó Proyecto Humedal de los Carrizales y se llevó a cabo mediante la creación de una laguna de aguas someras permanentes que favorezca la presencia de especies ornitológicas amenazadas asociadas a este medio, la reproducción de peces y la recuperación de la vegetación de ribera. Tras la construcción de la charca de Manzanilla por parte de $\mathrm{AHSA}^{7}$, se abordó la implantación de la charca de "El Prado" mediante una colaboración de los grupos conservacionistas ANSE y AHSA junto a la Comunidad de Regantes de Carrizales. Su superficie es en la actualidad de dos hectáreas, estando proyectada una futura ampliación de dos hectáreas más.

- Anillamiento de paseriformes en Los Carrizales: Jornadas financiadas por la Fundación Biodiversidad del Ministerio de Agricultura, Alimentación y Medio Ambiente.

- Liberación de galápagos: acción llevada a cabo por ANSE en la charca de "el Prado".

- Liberación de anátidas: suelta efectuada por la Conselleria de Medio Ambiente en la charca de "El Prado".

- Firma de un acuerdo de custodia del territorio en 2009 para favorecer la reproducción de la canastera común (Glareolapratincola): Acuerdo de Custodia a tres bandas, AHSA, la Propiedad y la Comunidad de Regantes de Carrizales sobre la finca Roque Pérez - Lo Cabello, que tiene una extensión aproximada de unas 50 Ha. Se trata de unos terrenos agrícolas de regadío que son cultivados con la tradicional rotación de cultivos: alfalfa - cereal - barbecho, manteniéndose sin cultivar una parte de ellos por la falta de agua de riego. El objetivo principal de este acuerdo es proteger y facilitar la presencia de la Canastera que, en las amplias parcelas de barbechos de esta zona, encuentra un adecuado lugar para nidificar y alimentarse. El acuerdo consiste básicamente en el compromiso por parte de la Propiedad de labrar las parcelas sin cultivar, con anterioridad a la llegada de las canasteras de sus áreas de invernada en África, además de evitar la realización de tareas agrícolas durante la época de nidificación en las zonas donde se instala el ave, 
así como eludir el uso de herbicidas en el control de la vegetación de las azarbetas, de las lindes de los campos y de los caminos de esta finca.

Por parte de la Comunidad de Regantes, se asume el gasto del labrado de las tierras sin cultivar. AHSA redactará un informe anual con los resultados del seguimiento de los valores ambientales de la finca, para que pueda ser utilizado para la puesta en valor de Los Carrizales de Elche.

- Reforestación arbórea de la zona y revegetación de márgenes y costones: Acción lleva a cabo conjuntamente por AHSA y ANSE. Durante esta jornada se reforzó las plantaciones de Junco y castañuela (Scirpus sp) en las orillas de la charca de "El Prado" y se realizaron acciones de control del carrizo y de las islas.

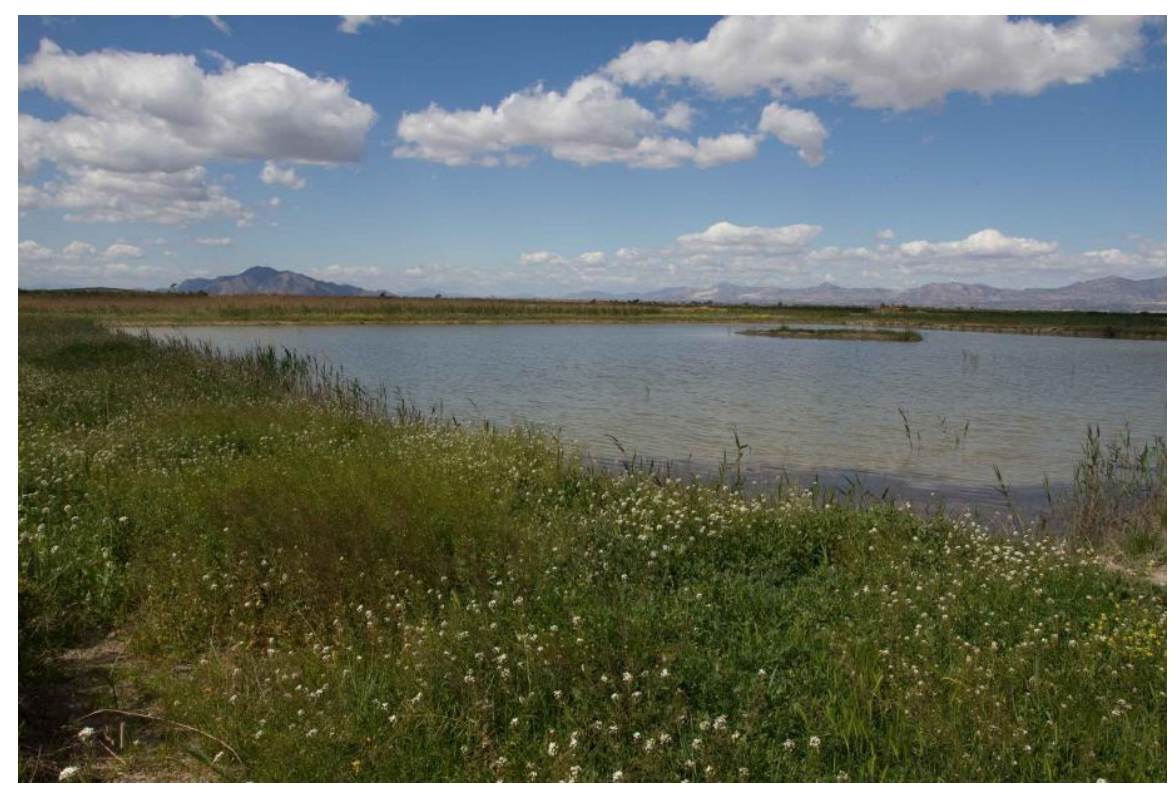

Fig. 10: La charca del Prado, creada con la colaboración de las asociaciones ecologistas AHSA y ANSE.

La difusión de este tipo de actividades a través de los medios de comunicación hace que la marca sea conocida a nivel local, lo cual es necesario para dar a conocer el producto. A medida que aumente la demanda de producto se aumentará la oferta del mismo, preferentemente a ser posible por incorporación de nuevos agricultores a la cooperativa.

Si bien el futuro de la producción tenderá a ser ecológica a largo plazo, por mera coherencia con los principios del proyecto, eso no es algo que se considere necesario a corto y medio plazo, pues un estudio de la producción y venta en los parques agrarios más próximos nos revela que los productos se venden más por la asociación de una marca con un territorio que el consumidor reconoce como propio, que por el hecho de que el producto sea ecológico. Por otra parte, el conformarnos con una producción inicial integrada hará que se facilite la incorporación de nuevos agricultores al proyecto al liberarlos de los procesos burocráticos y cargas administrativas que lastran la producción ecológica.

De cara al futuro cabe destacar que al proyecto no le interesa la producción ecológica en sentido estricto sino la producción agroecológica. La diferencia entre ambas consiste en 
que la ecológica no implica necesariamente la existencia beneficios medioambientales indirectos, puesto que puede realizarse en invernaderos o en amplias superficies de monocultivo; mientras que la agroecológica es inseparable del mantenimiento del paisaje, el patrimonio histórico-cultural y la defensa de la biodiversidad.

Por otro lado, el cultivo en parcelas agroecológicas implica una mayor atención y dedicación del agricultor, lo que dificulta la entrada en el proyecto de grandes empresas agroindustriales, y favorece la rentabilidad del minifundismo tan extendido por la zona.

Se está estudiando la posibilidad de recuperar cultivos tradicionales, algunos desparecidos hace tiempo, como el de las plantas soseras y barrilleras, y en general de cultivos y recursos naturales que han caído en el olvido. Con el fin de tener una base de datos de referencia, sobre la cual poder plantear iniciativas al respecto, en 2010 se encargó un estudio a la Universidad de Alicante sobre las plantas de interés etnobotánico de nuestro ámbito ${ }^{8}$.

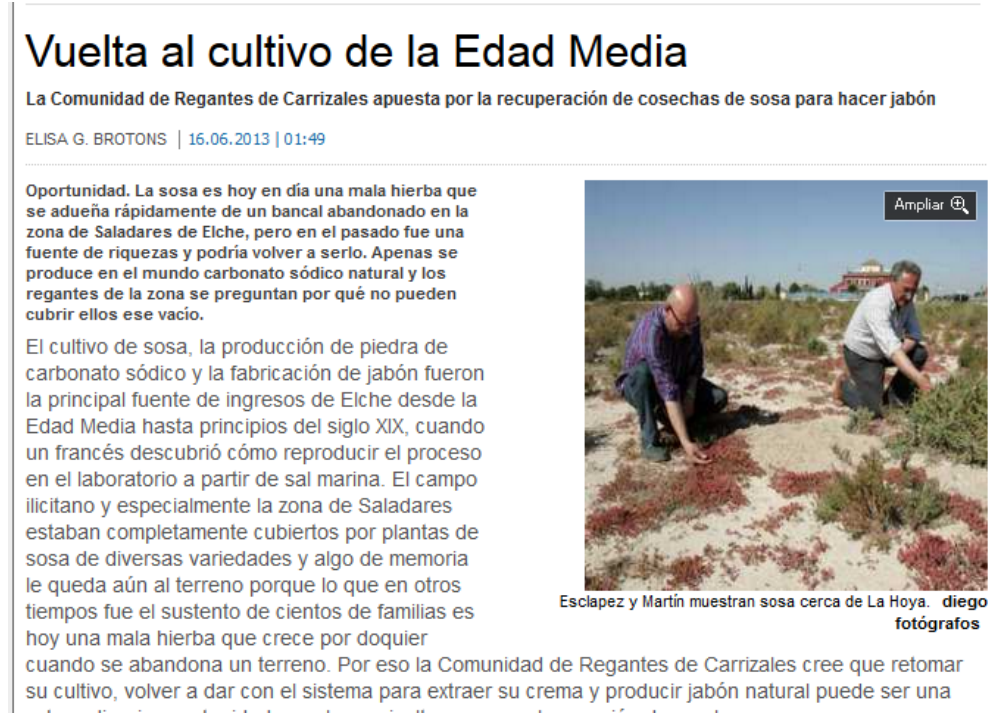

Figura 11. Noticia en el periódico información sobre el proyecto de recuperación del cultivo y producción de la sosa en Carrizales, en colaboración con miembros de la Universidad de Alicante

\section{Discusión final}

Hemos trabajado mucho durante estos siete años, y muchas veces hemos estado a punto de caer en el desaliento ante las incomprensiones, los obstáculos administrativos o legales, muchas veces absurdos, ante ciertas actitudes también prepotentes, y ante la dejadez, el desinterés por la conservación del patrimonio. Pero ha habido muchas personas, también en la administración, que nos han animado a seguir adelante. Y en eso estamos.

Hemos conseguido que se hable del Camp d'Elx y que la prensa entre diciembre de 2007 y todo el 2008 accediese a escribirlo con nombre propio (¡ni reconocían el nombre en valenciano!)

Hemos conseguido que se visibilice el Camp d'Elx , en parte, como medio rural que es y que como tal se le empiece a respetar y a tener en cuenta, que se tenga en cuenta el Territorio en su conjunto, que se empiece a respetar el patrimonio (sea de la tipología que 
sea), que se vea a las personas como parte necesaria del paisaje, incluso en las zonas protegidas como Carrizales.

No hemos conseguido ni la revisión del PGOU del municipio, ni que se cierre un Vertedero la lado del Parque Natural del Hondo nique se dejen de cementar azarbes, ni tener alojamientos rurales legales y reglados por turismo (base de cualquier producto turístico)...

Pero uno de los objetivos esenciales, y el que parece ser el mayor logro hasta la fecha, a falta de publicarse en el Boletín Oficial de la Generalitat Valenciana próximamente, es el de que el Camp d'Elx sea simplemente reconocido de forma "oficial" y "administrativa" por lo que es y ha sido siempre: territorio rural, medio rural, campo. Algo que puede resultar inaudito en el año 2014 nos estaba pasando desde que somos considerados compañeros de una gran ciudad, no parte de un territorio amplio y diverso, magnífico: parte de la comarca del Baix Vinalopó, el municipio de Elche.

El que desde los años 50 del s.XX Elche se convirtiese en referente de la industria manufacturera con el calzado y la agricultura se viese desplazada, el que se valore más la creación de 100 o de 1000 puestos de trabajo que el de 20 en el campo (aunque haya actualmente casi más comercializadoras de calzado que fábricas), ha conllevado entre otras diversas y variadas razones a considerar el campo como algo anexo, subsidiario, no relevante, donde ir a comer los domingos o tener la "faeneta" para el verano, invisibilizando el que siguiese cultivándose y trabajando con cultivos de gran rentabilidad como los granados o con hortalizas y verduras de verano e invierno, invisibilizando grandes patrimonios relacionados con el agua, o con la naturaleza, como los Parques Naturales, invisibilizando a sus habitantes, tradiciones y deseos (no de todos, pero sí de muchos).

El que nuestros administradores locales y autonómicos durante años y años, más de 20, y hasta hace escasos meses no se hayan puesto a defender este territorio en su conjunto para recuperar la identidad que siempre ha tenido y su lugar en la planificación y gestión en el ámbito del desarrollo rural, dice mucho sobre la opinión que los gestores "urbanitas" han tenido sobre el medio rural. Ni la Ley sobre Medio Rural del año 2007 nos acercó a las posiciones de otras comarcas con la agricultura periurbana.

El que fundásemos ADR Camp d'Elx en 2007, el que Carrizales se constituyera en Parque Natural Agrario, tenía y tiene un fin claro: reivindicar aquello que siempre hemos sido: medio rural, y hacer que lo que produzcamos ya sean bienes o servicios redunden en la propia comunidad del medio rural, el método sería y es el turismo rural como actividad económica transversal que a través del desarrollo rural permita incentivar y mejorar todos los ámbitos: agricultura, venta en el canal corto de productos, turismo de naturaleza, artesanía, señalética, mejora y conservación del patrimonio y un largo etcétera.

Desde entonces la cantidad de peticiones, reuniones, informes, dossieres, visitas, persecución de técnicos y políticos ha sido larga e ingente por parte de gran cantidad de miembros de la asociación, sin cargo ni remuneración, y aún a falta de informes y estadísticas de detalle, aún a falta de imprimir el documento a color o en blanco y negro, lo importante era presentarlo, reivindicarlo una y otra vez, insistir, de ahí que hayamos visto pasar a Directores generales, a Secretarios autonómicos, a Alcaldes, a Consellers, a Presidents....y no hemos dejado de pedir y reivindicar lo mismo: estar, formar parte de... 
El primer escalón está prácticamente conquistado, el impulso para subir la escalera lo tenemos y lo que puede resultar increíble, que te reconozcan quién eres y dónde estás, se está consiguiendo. Pero aún nos queda mucho por sacar a la luz, aún nos quedan muchas cosas que enfocar, valorizar y visibilizar. Tendremos queluchar todos los días contra propuestas destructoras de nuestro patrimonio, contra decisiones administrativas e intereses contrarios a la sostenibilidad ambiental, contra agresiones múltiples, ... el camino sigue, el camino sigue desde el sur hacia el norte.

Pero hemos conseguido que la Administración Autonómica y la local reconozcan el Medio Rural, que se admita oficialmente que el Camp d'Elx existe como ámbito rural en 2014 ¡iEs nuestro mayor logro!!

\section{Referencias}

Arroyo, S. (2010): La charca de Manzanilla, de vertedero a zona húmeda. La Matruca (Publ. de la Asociación de Amigos de los Humedales del Sur de Alicante, AHSA), 20: 40-51.

Belda Antolí, A. (2011): Inventario de plantas con interés etnobotánico en la partida de Carrizales (Elche). Informe inédito. Alicante: Universidad de Alicante.

Guilló Durá, M., Martín Cantarino, C. (2010): El manifest de Guardamar: una crida pel futur del nostre sistema de regadiu i els seus valors culturals, socioeconòmics i ambientals. La Rella (Anuari de l'Institut d’Estudis del Baix Vinalopó), 23: 219-324.

López Pomares, A. (2008): Influencia de las características de los canales de riego sobre la ornitofauna en época de cría en el entorno de los Parques Naturales de El Hondo y las Salinas de Santa Pola. Memoria de Diploma de Estudios Avanzados (D.E.A.). Inédita. Alicante: Universidad de Alicante

Martínez García, R. (2010): Sénies i molins: algunes reflexions sobre el projecte WADI i el patrimoni. La Rella (Anuari de l'Institut d'Estudis del Baix Vinalopó), 23: 139-153.

Martín Cantarino, C. (2006): Escenaris de futur per al Fondo i el seu entorn. Presentació del Projecte WADI, La Rella (Anuari de l'Institut d'Estudis del Baix Vinalopó), 19: 327-339.

Martín Cantarino, C. (2013): Los azarbes, piezas clave de nuestro sistema de zonas húmedas. La Matruca (Publ. de la Asociación de Amigos de los Humedales del Sur de Alicante, AHSA), 23: 4-17.

Ramos J., Fidel, L., Arroyo, S., Aldeguer, O. (2005): Las aves de Els Carrissars d'Elx. La Matruca (Publ. de la Asociación de Amigos de los Humedales del Sur de Alicante, AHS A), 15. 